\title{
Molecular Cloning and Characterization of the Human VGF Promoter Region
}

\author{
Nadia Canu, Roberta Possenti, Anna Maria Rinaldi, Eugenia Trani, and *Andrea Levi \\ Dipartimento di Medicina Sperimentale e Scienze Biomediche, Seconda Università di Roma Tor Vergata; \\ and *Institute of Neurobiology, CNR, Roma, Italy
}

\begin{abstract}
The VGF gene encodes a secretory protein that is expressed in a cell type-restricted pattern in neuroendocrine cells and is up-regulated by nerve growth factor (NGF) in the rat pheochromocytoma PC12 cell line. Here we report the isolation and characterization of the $5^{\prime}$ terminal region of the human VGF gene. In addition to a TATA box and a CCAAT box located at canonical distances from the transcription start site, the human VGF promoter contains several consensus sequences for different transcription factors, including a cyclic AMP response element and an AP-1 element, several GC boxes, and sequences homologous to other neuronal promoters. Transient transfection analysis demonstrates that $2.3 \mathrm{~kb}$ of the $5^{\prime}$-flanking sequence acts as a tissue-specific promoter, efficiently used only by neuronal cells that express endogenous VGF. Deletion analysis reveals that a positive regulatory region is located between nucleotides -458 to -204 . Negative cis-acting elements that repress promoter activity in cell lines that do not normally express VGF are located between nucleotides $-2,305$ and -573 and between -458 and -204 . The $5^{\prime}$-flanking region of the human VGF gene confers responsiveness to NGF, cyclic AMP, and phorbol ester treatment. Key Words: VGF gene-Secretory protein-Tissue-specific transcription-Cyclic AMP response element.

J. Neurochem. 68, 1390-1399 (1997).
\end{abstract}

The $V G F$ rat gene encodes a protein expressed specifically in subpopulations of neuron and endocrine cells. The physiological function of $V G F$ remains to be established, although its cleavage by endoproteolytic enzymes of the secretory pathway and the regulated release of the processed products suggest that $V G F$ is the precursor of peptides involved in intercellular communication (Liu et al., 1995; Trani et al., 1995). The expression of the gene is developmentally regulated: In the cerebellum $V G F$ mRNA levels peak during a critical period of morphological and functional organization (Salton et al., 1991) and are spatially and temporally modulated during the synaptogenesis of geniculocortical afferents (Lombardo et al., 1995). In addition, VGF is a neurotrophin-responsive gene being up-regulated by nerve growth factor (NGF) in PC12 cells (Levi et al.,
1985 ) and by brain-derived neurotrophic factor and neurotrophin 3 in primary cultures of cortical or hippocampal neurons (Bonni et al., 1995). In vivo protein and mRNA levels are modulated in different areas of the brain in response to salt loading ( $\mathrm{S}$. K. Mahata et al., 1993a), adrenalectomy (S. K. Mahata et al., 1993b), reserpine treatment (Laslop et al., 1994), and lesions of the septohippocampal cholinergic pathway (M. Mahata et al., 1993). It was recently shown that transcription of $V G F$ is modulated in gonadotropic cells during the estrus cycle (Ferri et al., 1995). Previous studies on the $V G F$ rat gene have demonstrated that regulatory elements directing tissue-specific expression and induction by NGF and cyclic AMP (cAMP) are located between -600 and +40 with respect to the transcription initiation site (Possenti et al., 1992). Furthermore, the same region is able to direct the correct spatiotemporal expression of a linked gene in transgenic mice (Piccioli et al., 1995). In this study we have examined several aspects of human $V G F(h V G F)$ gene expression, including the molecular analysis of regulatory elements that influence the cell type-specific expression and the induction of the gene by cAMP and 12-O-tetradecanoylphorbol 13-acetate (TPA).

\section{MATERIALS AND METHODS}

\section{Genomic clone isolation and sequencing}

Approximately 500,000 plaques of a human genomic library (EMBL-3SP6/T7; Clonotech) were screened by filter hybridization using a random-labeled ${ }^{32} \mathrm{P} h V G F$ cDNA clone

Received August 2, 1996; revised manuscript received December 12, 1996; accepted December 12, 1996.

Address correspondence and reprint requests to Dr. A. Levi at Istituto di Neurobiologia, CNR, Via le Marx 43,00137 Roma, Italy.

Abbreviations used: cAMP, cyclic AMP; CAT, chloramphenicol acetyltransferase; CRE, cyclic AMP response element; $C R E B$, cyclic AMP response element-binding protein; dbcAMP, $N^{6}, 2^{\prime}$ - $O$-dibutyryladenosine $3^{\prime}: 5^{\prime}$-cyclic monophosphate; $h V G F$, human $V G F ; \mathrm{NGF}$, nerve growth factor; SDS, sodium dodecyl sulfate: SSC, salinesodium citrate; TPA, 12-O-tetradecanoylphorbol 13-acetate. The nucleotide sequence of the $h V G F$ promoter region has been submitted to the EMBL Nucleotide Sequence Database and assigned accession no. Y09938. 
as the probe (Canu et al., 1992). Prehybridization and hybridization were performed in $50 \%$ formamide, $5 \times$ salinesodium citrate (SSC), $1 \%$ sodium dodecyl sulfate (SDS), $1 \times$ Denhardt's solution, and $200 \mu \mathrm{g} / \mathrm{ml}$ salmon sperm DNA at $42^{\circ} \mathrm{C}$. Filters were washed twice in $2 \times \mathrm{SSC}$ with $0.1 \%$ SDS at $65^{\circ} \mathrm{C}$ and twice in $0.2 \times \mathrm{SSC}$ with $0.1 \%$ SDS at $65^{\circ} \mathrm{C}$. Upstream regulatory sequences were isolated based on sequence homology with the rat promoter. In brief, a positive clone named DCA1, containing a $22-\mathrm{kb}$ insert, was digested with restriction enzymes, blotted onto nylon membranes, and hybridized under stringent conditions with a probe containing a fragment of the rat $V G F$ promoter from positions -805 to +41 with respect to the initiation site. A single EcoRI-XhoI restriction fragment of $3 \mathrm{~kb}$ hybridized with the probe and was subcloned into (pBluescript) KS to create the pKShVGF promoter vector. Nested deletion from the polylinker sequences at the $5^{\prime}$ and $3^{\prime}$ ends of the insert was done by the EXO III-S1 method using the Erase-A-base kit (Promega Biot). The resulting clones were double-strand sequenced using the Sequenase dideoxy kit (U.S. Biochemical) and oligonucleotide primers based on previously acquired sequence information. In the GC-rich regions a protocol based on the use of Taq polymerase was used. Analyses of nucleotide sequences were performed with Intelligenetic (Ig) Molecular Biology Software. The current FASTA program was used for searching nucleic acid sequence similarities.

\section{Primer extension}

The transcription initiation site was mapped by primer extension using a 24-mer oligodeoxynucleotide complementary to nucleotides +174 to +191 in the $\mathrm{hVGF}$ sequence NC-40 (5'-AGCTGGTGTCACGACGCGAGAGGT-3'). The $\left[\gamma-{ }^{32} \mathrm{P}\right] \mathrm{dATP}-$ labeled oligonucleotide was annealed at $70^{\circ} \mathrm{C}$ with $2 \mu \mathrm{g}$ of SK-N-BE poly $(\mathrm{A})^{+} \mathrm{RNA}$ or $20 \mu \mathrm{g}$ of HeLa RNA and extended at $37^{\circ} \mathrm{C}$ for $2 \mathrm{~h}$ using 100 units of M-MLV reverse transcriptase (Promega). Following digestion with RNase A the extended products were analyzed on $6 \%$ polyacrylamide-urea gels along with a dideoxy DNA sequencing reaction of $\mathrm{pKShVGF}$ performed with the same oligonucleotide as primer.

\section{Construction of reporter genes for $h V G F$ promoter activity}

A plasmid named pKShVGF was constructed consisting of the sequence of the $h V G F$ gene from $-2,305$ to +51 , cloned in pKS between the Xhol and BamHI sites. This was used to produce expression vectors for the $h V G F$ promoter. The cDNA sequence coding for chloramphenicol acetyltransferase (CAT) was excised as a BamHI-Xbal fragment from pEMBL-8-CAT (Dente et al., 1983) and cloned in pKShVGF to generate $-2.3 \mathrm{CAT}$. Serial deletions of the $5^{\prime}$ flanking region of the $h V G F$ gene were obtained using the unique Xhol site in the -2.3CAT plasmid and appropriate restriction sites in the upstream region of the $h V G F$ gene: BglII (-573CAT), SacI (-204CAT), and AatII (-70CAT). To construct the $\triangle$ CRE mutant, the plasmid $-2.3 \mathrm{CAT}$ was digested at a unique AatII site within the cAMP response element (CRE) and treated with T4 DNA polymerase. Sequence analysis demonstrated that 5 bases spanning the CRE were deleted. The $\triangle$ CRE-2.3CAT was digested with $S a c I-X b a I$, and the resulting fragment, containing -204 to +52 of the $V G F$ promoter plus the 1,650 bp of the CAT gene, was introduced into the $S a c \mathrm{I}$ and $\mathrm{Xbal}$ sites of pSK to create $\triangle$ CRE-204CAT. Two plasmids
(hVdSCAT 1 and $\mathrm{hVdSCAT2}$ ) that contain the region of the $h V G F$ gene from -573 to -204 cloned in both orientations upstream to the chicken $\beta$-actin promoter CAT plasmid were produced as follows. The sequence from -573 to -204 from the hVGF sequence was amplified by polymerase chain reaction with a 5 '-primer oligonucleotide complementary to positions -584 to -567 and containing a $B g / I I$ restriction site and a 3 '-primer oligonucleotide complementary to positions -222 to -204 and including a $B a m H I$ restriction site. The PCR product was cut with $B g / \mathrm{II}$ and $B a m \mathrm{HI}$ and subcloned into the BamHI site of the chicken $\beta$-actin promoter CAT plasmid (Quitschke et al., 1989). The insert orientation with respect to the actin promoter was screened by restriction analysis, and the constructs were verified by sequencing.

\section{Cell cultures}

PC12 pheochromocytoma cells were cultured in RPMI medium with $5 \%$ fetal bovine serum and $10 \%$ horse serum (GIBCO). The human neuroblastoma cell lines IMR-32 and CHP-100, the murine neuroblastoma cell line NIE-15, the BOSC 23 cell line (gift of Dr. W. S. Pear), and the NIH3T3 line were maintained in Dulbecco's modified Eagle's medium with $10 \%$ fetal bovine serum (GIBCO). Human neuroblastoma SK-N-BE cells were grown in RPMI medium with $10 \%$ fetal bovine serum. All culture media were supplemented with penicillin $\mathrm{G}$ ( 100 units $/ \mathrm{ml})$ and streptomycin $(100 \mu \mathrm{g} / \mathrm{ml})$. NGF was kindly provided by Dr. D. Mercanti. TPA and cAMP were purchased from Sigma.

\section{Cell transfection and reporter gene assay}

Cell transfections were performed by liposome-mediated gene transfer using Lipofectamine (GibcoBRL). Transfection of expression construct DNAs with the positive control RSV-CAT (Gorman et al., 1982) and the negative control promoterless plasmid pKS-CAT was done in parallel experiments in all cell lines. At $48-72 \mathrm{~h}$ after transfection, cells were harvested, and CAT activity was determined by dualphase diffusion assay (Neumann et al., 1987). CAT activity was normalized to the amount of plasmid DNA present in each extract of transfected cells, as determined by dot blot hybridization using the pKS vector as a probe. In $N^{6}, 2^{\prime}-O$ dibutyryladenosine $3^{\prime}: 5^{\prime}$-cyclic monophosphate (dbcAMP), TPA, and NGF induction experiments, $5 \mu \mathrm{g}$ of plasmid was used per 65 -mm-diameter dish. At $24 \mathrm{~h}$ after transfection, cells were divided and treated with $1 \mathrm{~m} M$ dbcAMP, $0.1 \mathrm{~m} M$ TPA, or $100 \mathrm{ng} / \mathrm{ml} \mathrm{NGF}$ for $24-36 \mathrm{~h}$.

\section{Western blot analysis}

Cell extracts and western blot analysis were performed as described by Trani et al. (1995).

\section{RESULTS}

\section{Isolation and nucleotide sequence of 5 '-flanking region of $h V G F$ gene}

Screening of a human genomic library with a cDNA probe for $h V G F$ resulted in the isolation of several independent clones that were analyzed by restriction mapping and Southern blot hybridization using $h V G F$ cDNA, rat $V G F$ cDNA, and rat genomic sequences as probes (see Materials and Methods). One of these clones, named DCA1, was chosen for further characterization. A single 3-kb fragment of an EcoRI-XhoI digest of DCA 1 hybridized with sequences correspond- 
ing to the promoter region of the rat $V G F$ gene, and this fragment was subcloned into pKS for sequence analysis. The nucleotide sequence of the $h V G F$ promoter and its comparison with the rat $V G F$ gene are shown in Fig. 1. Inspection of the human sequence revealed upstream of the +1 transcription start site a TATA box-like sequence (TTTATAA) starting at base -29 and a CCAAT box at base -135 . A consensus binding site for CRE-binding protein (CREB) was identified at position -76 , and it was found in the context of an element with dyad symmetry ( -79 CATTGACGTCAATG-66). In addition, the human promoter gene contained several GC boxes $(-65,-108$, $-1,047$, and $-1,899)$; inverted GC motifs ( -260 , $-1,194$, and $-2,250$, with the one at -260 overlapping with an AP-2 binding site); 14 CCCTCCC boxes, a potential binding site for $\mathrm{Sp}-1$ transcription factor $(-362,-478,-882,-923,-1,004,-1,221,-1,279$, $-1,283,-1,551,-1,813,-1,952,-2,020,-2,053$, and $-2,057) ; 15$ potential AP-2 binding sites $(-44$, $-174,-264,-946,-1,007,-1,086,-1,117,-1,193$, $-1,201,-1,328,-1,352,-1,551,-1,953$, and $-2,249)$; and an inverted Ap-2 binding site ( -523 overlapping with a PuF binding site). The sequence starting at position - 953 fit the consensus binding sequence of the transcription factor AP-1 (TGAGTCA) and is adjacent to an Ap-2 binding site. In addition, we identified nine CANNTG motifs, which are potential target sites for the helix-loop-helix family of transcription factor. Table 1 summarizes the potential binding sites for known transcription factors found within the $-2,305$ to +51 sequence of the $h V G F$ gene. Two motifs that are present in several neurospecific genes were found in the $5^{\prime}$-flanking region of $h V G F$. The core motif CCAGGAG, common to genes encoding mouse neurofilament (Lewis and Cowan, 1986), rat peripherin (Thompson and Ziff, 1989), rat GAP-43 (Nedivi et al., 1992), rat SCG10 (Mori et al., 1990), rat type II $\mathrm{Na}^{+}$channel (Maue et al., 1990), and mouse synapsin II (Chin et al., 1994), is present at position -867 on the coding strand of $h V G F$. A silencer element similar to that associated with rat SCG10, rat type II $\mathrm{Na}^{+}$channel, human and rat synapsin I ( $\mathrm{Li}$ et al., 1993), and the human dopamine $\beta$-hydroxylase gene (Ishiguro et al., 1993) was also found in the $h V G F$ flanking region at position -411 . The repetitive motif TTCA, widely dispersed in the mouse and human genome, was also found scattered in a region of $\sim 200$ nucleotides immediately downstream of the silencer element described above.

Regions conserved between the $h V G F$ and rat $V G F$ genes, which may therefore provide regulatory functions for VGF transcription, were found dispersed throughout the entire promoter region. The rat and human sequences showed a $>80 \%$ overall homology over a length of $800 \mathrm{bp}$. A region of high homology is situated between nucleotides -440 and -208 , which contains the tandem repeat of the tetranucleotide TTCA, the putative silencer element $(-411$ to -388$)$, and the GC box mentioned above. Notable differences between the human and rat promoter regions include the absence in the rodent gene of the NF- $-\mathrm{B}$ box and the absence in the $h V G F$ promoter of the E-box at position -167 in the rat gene. This motif is involved in the transcriptional regulation of the rat $V G F$ gene (Di Rocco et al., 1997).

\section{Determination of $h V G F$ gene transcriptional initiation site}

The transcription start site for the $h V G F$ gene was determined by primer extension of poly $(\mathrm{A})^{+}$RNA isolated from the human SK-N-BE cell line. Primer extension resulted in a single band, indicating that one single site was used for the start of transcription. This site $(+1)$ was located 29 residues downstream of the first $\mathrm{T}$ of the TTTATA box. No extension products were observed when the reactions were performed with HeLa cell RNA (Fig. 2).

\section{The 5'-flanking sequence directs cell-specific reporter activity in a transient expression assay}

To assess whether the 5'-flanking region of the $h V G F$ gene contained information sufficient for cellspecific expression, we made the gene fusion construct $-2.3 \mathrm{CAT}$, inserting the $2.3-\mathrm{kb} 5^{\prime} V G F$ flanking sequence (from $-2,305$ to +51 ) in front of the bacterial CAT gene in pKShVGF (Fig. 3A). The construct was transfected into several nonneuronal (BOSC 23, NIH3T3, and $\mathrm{LTk}^{-}$) and neuronal (SK-N-BE, PC12, NIE115, CHP-100, and IMR32) cell lines that differed with respect to the amount of endogenous VGF. Each cell line was transfected in parallel with pKS-CAT, containing the promoterless CAT gene, and pRSVCAT, containing the CAT gene under the control of the RSV long-terminal repeat. pRSV-CAT was strongly active in all cell lines analyzed, and the transcription of the $h V G F$ gene was expressed as a percentage of RSV promoter activity. Transcription of the transfected human promoter was compared with the steady-state level of $V G F$ mRNA (data not shown) and VGF protein as measured by western blot (Fig. 3C). Substantial CAT activity was detected in all cell lines that express endogenous VGF. These were the human neuroblastoma cell line $\mathrm{SK}-\mathrm{N}-\mathrm{BE}$, the mouse neuroblastoma cell line NIE-115, and the rat PC12 line. In contrast, cell lines in which the VGF protein content was below the detection limit showed only minimal CAT activity from $-2.3 \mathrm{CAT}$ (Fig. 3B and C). This finding held true even for neuronal cell lines like the human neuroblastoma IRM32 and CHP-100, consistent with the fact that VGF is a neuroendocrine-specific protein expressed in selected neuronal populations (Rossi et al., 1992).

The human 5'-flanking region was inducible by NGF in PC12 cells, as previously shown for the rat $V G F$ promoter (Fig. 3B).

\section{Both positive and negative regions contribute to} cell type-specific expression of the $h V G F$ gene

The preferential expression of $-2.3 \mathrm{CAT}$ in a subset of neuronal cells suggested that the $2.3-\mathrm{kb}$ promoter/ 
FIG. 1. A: Nucleotide sequence of the 5 '-terminal region of the $h V G F$ gene. The transcription initiation site $(+1)$ is indicated by the arrow. Transcription factor binding sites are underlined, and their names are indicated above. A sequence found in other neurospecific genes (Maue et al., 1990) is double underlined. A 23-bp segment homologous to the NRSE described by Maue et al. (1990) and Mori et al. (1990) is in boldface. Nucleotide sequences sharing significant homology with previously characterized tissue-specific cis-acting element are boxed, and their names are indicated above. The TTCA repeat sequence is dotted underlined. B: The $5^{\prime}$-flanking regions of the $h V G F$ and rat VGF genes are compared. The upper sequence corresponds to that of hVGF gene, whereas the lower sequence is that of the rat gene (Salton et al., 1991)
(A)

$$
5 P-1 / A P-2
$$

CTCGAGGATCTGATTAAATACACAATTGCTTCCCCCCATTCCCTTICTTITTCTCCCCGCCCCGGCCATG -2236

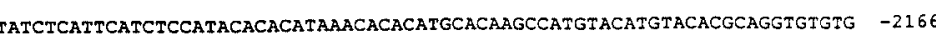
TGCATACACAAGCCAACAGGCAAATACAGTTTCTCCAGGTGCCTGTCTTCTCTCATCTTGCAACTIGGTC -2096 Sp-1/Sp-1
TCTGATCCCCATCAGCCACTCAGTCAGCCCCCTTGGCFCCRCECTCCCCTCTCCCTTCTCTCTTGGATG -2026 Sp-I
GGTTCCCOTCCCCCTCTCCAGATGTCTGAGCCATCTTCTCTCTGATZCATCCTCCTCAGGAAGGAACGTG -1956 $\begin{array}{ccc}\text { IL-6 REP } & 5 P-1 \\ \text { SP-1/AP-2 } & & \\ \text { ACCECCTCCCCCATCCCACTGCCTCTGTATCAGGCTGGGAAGATGAAGGGGACATGGGGGCGGGGAGAGGA } & -1886\end{array}$ AGGAGGGGAGGCCGTGGTTAGTTGTGCGTGGGGATGGGAGGCATTGCCTGGGGICTCCTACCCCTCTIT -1816

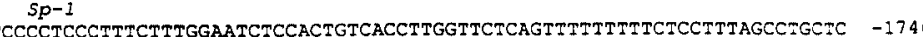
CTTCTACCTGTTCCAGATCCCTTCATTCCTTCCTCCTCCCCTGCCCCCATCTCTTCTCTCTITICTCCS: -1676 IL-6 RBP
CTCCACTCCTCCCCATTTCTTTCCCGCCAAGAGCTGATGGGCTIICTICIGGGABAGTCAGCCACTGAT $S p-1 / A p-2$

GGAAGCGAGAAGCCACTGCTGGTTATAGAGAGAAAGCACGTGAGTGTGTGTGTAGGGAGGGGGAGGT:AG -1536 AAGGAGGGTCAGTGCCAGGAAGAGGTGAGGAGGGGGGGGAGGACCGTTTCTGAAAGAGTCTCTAAGACCC -1466 TGACAGACAGCCCTGACCTTGGTTTCCAGAGTCTCAGGGTGCGGTGCCCTGCGTGTGCCCACAGAGCACC $\quad-1396$ AP-2
CCTATGTCCGCAGTTCGTGTGTGTCTGGCGTGTGTCATTGTATTCECCCCCCTTGGGTGCCCAGGCCCE $A P-2$ ECACCGCTCTCTGCCAGCACCGCAGCCCCCTCCAGGCTTCCTCECTCCETCCCCTTCATTCCTGCAG:5G -1256

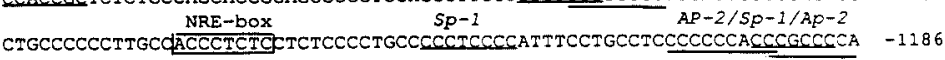
CGGCTGGTCTCCCTTGACCGGACCCAGCTCTCTGATGGATTCTCTTTGCGCAAATCTGTGCGTCATCGE - -1116

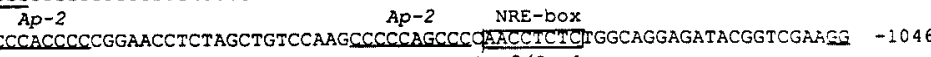
$S p-1 \quad A p-2 / S p-1$

GGCTGGTGGCAGAGAGGGGCTATCTCTGACGTTGCAGGTCCCCCTCCCATCGCGTTCAAACCTICCC:TI - 976

AAGCGGTGGAGAGAGCTGGAGTTGAGTCACCCCCCCCCCCACCTGCGCAACCCCCTECECACCTGCTCTG - 906 GTCTCGCCCTCCAAACGTCCTIGGGGGAGGGGAGCGGGCCAGGAGGGAAAGCGACTGGGGAGTGTGGSR̈A - 836 GAGATGGGGCCGAAGGGGGCACAGCGGGGGGCCTTGACACAAGCGGCAGTCAGGGGACAGAAGGACAGñC - 766 ACACCTTTTTCTCCAGACACAGCACGGATCGTGAAACAGACACGACCCAGAGGCACACACATCCTCATTC - 696 TTTCCCTTTTCTCTTCCGACTCGGACCCTTCCGATGGGATIACCAAAACCGCAAGATCCACCCATCTCCG - 626 CTGTCAGGGGCTGCACCCCGACTGCCCATICCGGGACAGCCGCAGGCGTGCAGATCTGTCCCTCTGCÃCT - 556 CAGGTTCACGCCGTCCTTGGGGCCGTGGTCTCGGGGTGGGGAACCGGCCCCTGGTCGGCTCTTGAATCTT - 486

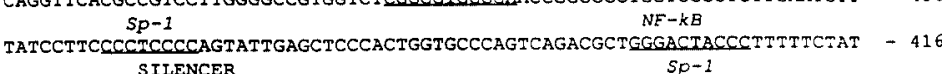

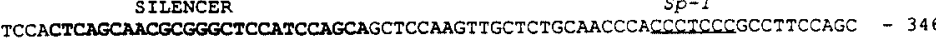
GCCTCTGCATCCACCCTTCCATTCATTCTCCCATTCATTCATTCATCCTTTTCTCCTCGTCCCTCCATCA - 276 Ap-2 $S p-1 \quad$ CTCCCTCAGCATITCATICATTCATTCATTCATTCATTTCCCGGAG - 206

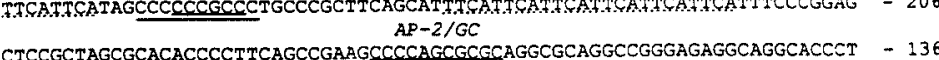
CRE
$\frac{S p-1}{\text { CCAAT }}$
CCAATCGTCGGGCGTCCTTCCTCCTCCGGSCGGCCGCCCGCTTCCCCATGAATGAACATTGACGTCAATG - 66 $\frac{\text { CCAATCGTCGGGCGTCCTTCCTCCTCCGGGCGECCECCCGC TATA-bOX }}{S P-1}$ AP-2/GC GGGCGGGGCGCGCCCACGTGACCCCGCGCGCTCCCCIITATAAGGCGGTGGAGGCGCGGGGCTGTCCAGC + (B) $-800$

AGGGAAAGCGACTGGGGAGTGTGGGAAGAGATGGGGCCGAAGGGGGCACAGCGGGGGG-CCTTGACACAAGCGGCA--. r: AAGCTTAAGGG---TGTGGGA-GAGTTGGATTAAAAGGGGGCACAACAGGGACCCCITATCAACCACACCAAA h: GICAGGGGA-CAGAaGGACAGACACACCTTTTTCTC--.------CAGACACAGCACGGATCGTGAAACAGACACGACC : GTCCGCTGGCCAGAAGGGCAGACACACCTITTTTCCCCACCCCCTTCAGAACTGGT--...-T TGAACAGACAGGACC CAGAGGCACACACATCCTCATTCTT

CACAGGCACACGCATCCTCATTCTTTCCCTTTTCTCTTCCGACTCGGACCC:-TCCGATGGGATTACCAAAACCOCAAGA CACAGCCACACGTATCGTCAATCTITCCCTTTTCTCTTCCGACTAGGACCCTITCCAAGgTGATtACCCAAACCGCAAGa TCCACCCATCTCCGCTGTCA--GGGGCTGCACCCCGACTGCCCATTCCGGGACAGCCGCAGGCGTGCAGATCTGTCCC-T h: TCCACCCATCTCCGCTGTCA--GGGGCTGCACCCCGACTGCCCAT:CCGGGACAGCCGCAGGCGTGCAGATC TGTCCC-I

: CTGCA-CTCAGGTTCACGCCGTCCTTGGGGCC-........-...-GTGGTCTCGGGGTGGGGAACC-GGCCCCT CTTCCTCTCAGGTTCAAGTCGTCCTTGGGCGTGCTCCCTATAGACCATACTGTGG---CGGAGTAGGGAGGCAGGCCCCT $-500$

: GGT-CGGCTCTTGAATCTTTATCCTTCCCCTCCCCAGTATTGAGCTCCCACTGGTGCCCAGTCAGACGCTGGGACTACCC TCCCCGGCTTTCAATCCCTTACCGTCCCCCCATCCAGTACTGATCTTTTAC.GGCGCCCAATTAGATGCTGOCGCTGCCC $-400$

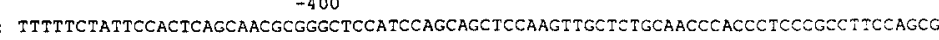
: tCtTCCTATTCTGCTCAGCAACGCGGGCTCCGCGCCT----CAAGA-GCT:TGTAACCCACC TCOCGCCT TCTGGCT

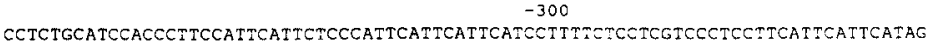
CCTCTGTACCCACCCTTCCATICATTTTTCCATTCATTCAITCATCCTITTCICCTCGTCCCTCCTTCATTCATTCATAG

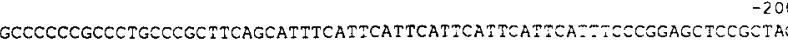

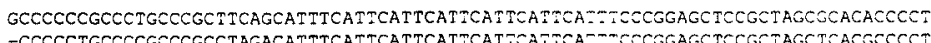

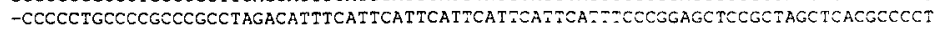
TCAGCCGAA-GCCCCAGCGCGCAGGCGCAGGCCGGGAGAGGCAGGCACCCTCOAATCGTCGGGCGTCC:TCCTCCTCCOG CTAGCCGAGGGCCCTACTGCGCAGGTOCAGGCCGGGAGCGACGCTIATCC. CCAATCATTGGACT TCCACAGTCCACCAG $-100$

: GCGGCCGCCCCGCTTCCCCATGAATGAACATTGACGTCAATGGGGCGGGGOGCGCCCACGTGACCCCGCGCOCTCCCCTTT : GCACCCGCCCGCTTCCCCATGAATGAACATTGACGTCAATGGGGCGSGGCGAGACCACG TGACCCCGCGCGCTCCCCTT TT ATAAGGCGGTGGAGGCGCGGGGCTGTCC

: ATAAAGCAGCGGTGGCGCGGGGOTGTCC 
TABLE 1. Transcription factor consensus binding sites within the $5^{\prime}$-flanking region of $h V G F$

\begin{tabular}{|c|c|c|}
\hline $\begin{array}{l}\text { Transcription } \\
\text { factor }\end{array}$ & Consensus sequence & Position $^{\prime \prime}$ \\
\hline AP-2 & YCSCCMNSSS & $\begin{array}{l}-44 ;-174 ;-264 ;-511(\mathrm{r}) \\
--946 ;-1,007 ;-1,086 ; \\
-1,117 ;-1.193 ;-1.201 ; \\
-1,328 ;-1,352 ; \\
-1,551(\mathrm{r})-1,953 ; \\
-2,249\end{array}$ \\
\hline AP-1 & TGAGTCA & -953 \\
\hline ATF/CREB & TGACG/TC/AG/A & -76 \\
\hline C/EBP & CCAAT & -135 \\
\hline E2A & RCANNTG & $\begin{array}{l}-51 ;-916 ;-1,569 ; \\
-2.207 ;-2,130 ;-2,175 ; \\
-2,207 ;-2.230 ;-2,283\end{array}$ \\
\hline GATA & WGATAR & $-1,026(\mathrm{r})$ \\
\hline $\mathrm{GCF}^{+}$ & SCGSSS & $-2,248$ \\
\hline KROX-E & GCACCCCGA & -613 \\
\hline$N F-k B$ & GGGAA/CTNT/CCC & -434 \\
\hline PAX- $8^{\prime \prime}$ & TGCCC & $\begin{array}{l}-1,225 ;-1,337 ;-1,410 \\
\quad-1,421\end{array}$ \\
\hline Pu-box & GAGGAA & $-1,890$ \\
\hline PuF & GGGTGGG & -522 \\
\hline \multirow[t]{2}{*}{ Spl } & GGGCGG & $\begin{array}{r}-65 ;-108 ;-260(\mathrm{r}) \\
-1,047 ;-1,194(\mathrm{r}) \\
-1,899 ;-2,250(\mathrm{r})\end{array}$ \\
\hline & CCCTCCC & $\begin{array}{l}-362 ;-478 ;-882(\mathrm{r}) ; \\
\quad-923 ;-1,004 ;-1,221 ; \\
\quad-1,279 ;-1,283 ; \\
-1.551(\mathrm{r}) ;-1,813 ; \\
-1,952 ;-2,020 ;-2,053 ; \\
-2,057\end{array}$ \\
\hline TBP & TATAA & -29 \\
\hline TCF- 1 & MAMAG & $-2,151$ \\
\hline IL-6-RE-BP & CTGGGAA & $-1,627 ;-1,922$ \\
\hline
\end{tabular}

Potential transcription binding sites present in the $h V G F$ promoter are noted. Consensus transcription factor binding sites were obtained from Faisst and Meyer (1992) except where indicated.

"(r), reverse complementary.

"From Zannini et al. (1992).

From DesJarden and Hay (1993).

regulatory region of the $h V G F$ gene contained elements for cell-selective gene transcription. To delineate the sequences required for this neural-specific expression a series of progressive deletions in the $h V G F 5^{\prime}$-flanking sequence was constructed ( see Materials and Methods and Fig. 4A). One VGF-expressing and one VGFnonexpressing cell line were chosen to measure the promoter activities of the different constructs by transient transfection assay. The results of these experiments are reported in Fig. 4B and are expressed as percentages of transcription activity relative to RSVCAT, corrected for the differences in transfection efficiency (see Materials and Methods). Deletion of the $h V G F 5$ '-flanking sequence between $-2,305$ and -573 resulted in a modest decrease in CAT activity in SKN-BE cells. A 2.5-fold elevation in reporter gene activity was observed in the VGF-nonexpressing cell line BOSC 23. This increase in $V G F$ promoter activity suggested the presence of a negative cis-acting element $(\mathrm{s})$ between $-2,305$ and -573 that interacted with factors present in these cells to repress transcription from the $V G F$ promoter. It is notable that the deleted region does not contain the putative silencer element described above, which is located $\sim 150$ bp downstream. The deletion of residues up to position -204 resulted in a drop in reporter gene activity in SK-N-BE cells and a threefold increase in CAT activity in BOSC 23 cells. These data suggested the presence of both positive and negative regulatory elements. A further deletion up to -70 (which affects the integrity of the CRE) slightly reduced promoter strength in SK-N-BE cells and resulted in a 2.5 -fold reduction in BOSC 23 cells. Deletion of the CRE in the context of the entire promoter had, by itself, no effect on transcriptional activity in either SK-N-BE or BOSC 23 cells, indicating that this sequence neither conferred transcriptional competence on the $V G F$ promoter in neuronal cells nor contributed to restrict its expression in nonneuronal cells (Fig. 4B).

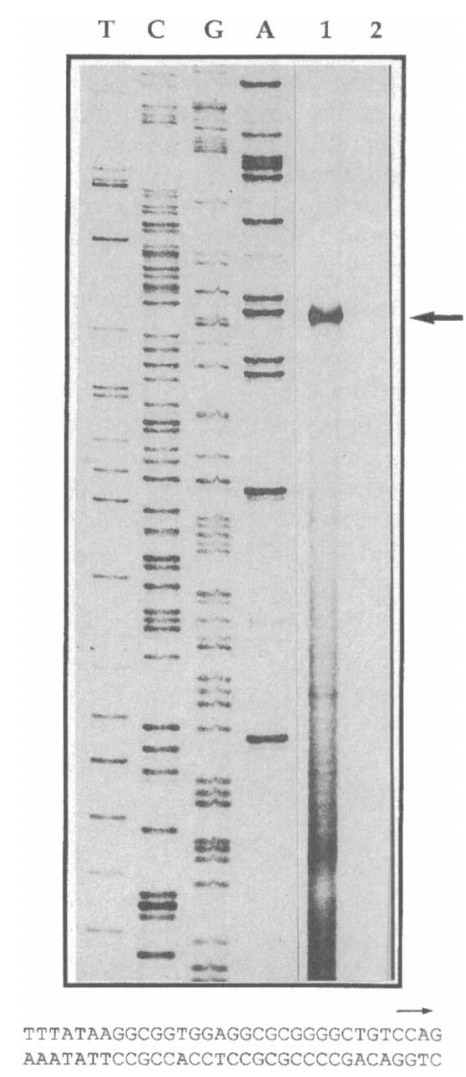

FIG. 2. Primer extension analysis of $h V G F$ mRNA. RNA from SK-N-BE cells (lane 1) and from HeLa cells (lane 2) were hybridized with an excess of polynucleotide kinase-labeled oligonucleotide $\mathrm{NC} 40$, and the extension reaction was performed as described in Materials and Methods. The products were analyzed on $6 \%$ acrylamide/ $7 \mathrm{M}$ urea. A DNA sequence ladder serves as a size marker. The arrow indicates the extension product of 191 nucleotides obtained with human neuroblastoma mRNA. The position of the TATAAG box in relation to the transcription start site is shown. 
Sequence -573 to -204 regulates transcription of a heterologous promoter

A 369-bp PCR fragment from position -573 to -204 was inserted in both orientations upstream to a heterologous promoter, to investigate further the dual role of this region in controlling VGF expression (Fig. 5A). When this sequence was cloned upstream to the basal thymidine kinase promoter of herpes simplex virus, the resulting plasmid exhibited very low activity on transfection in SN-K-BE cells (data not shown).

(A)

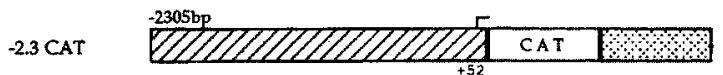

(B)

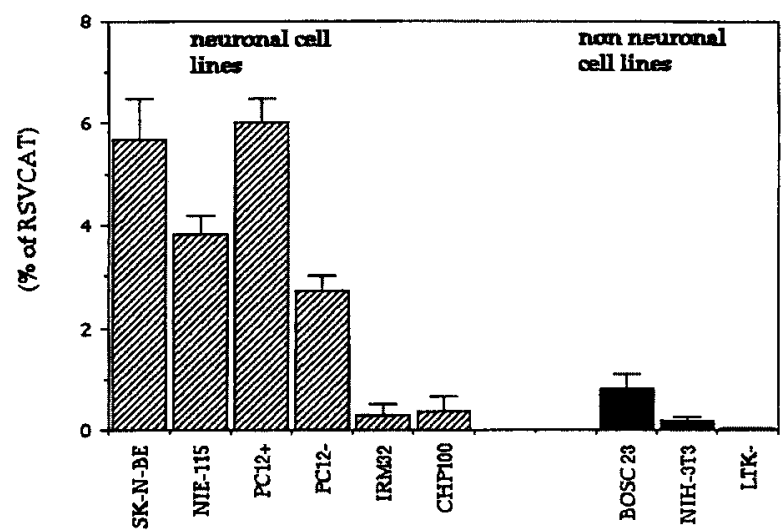

(C)

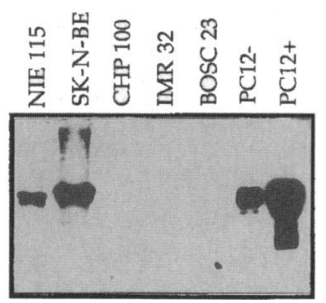

FIG. 3. Neuron-specific expression of the human VGF-CAT gene. A: Structure of the 2.3-kb fusion construct. The 5'-flanking sequence of the hVGF gene ranging from $2.3 \mathrm{~kb}$ to $+52 \mathrm{bp}$ (striped box) was linked to the CAT gene (open box). The arrow denotes the transcription initiation site. The dotted box indicates the SV40 polyadenylation site. B: Cell type-specific expression of the $-2.3 \mathrm{CAT}$ fusion gene in various neuronal and nonneuronal cell lines. CAT activities are shown as a percentage of RSV-CAT activity in parallel cultures. Data are mean \pm SEM (bars) values of the results from three or more independently transfected cultures. C: Expression of endogenous VGF in different neuronal and nonneuronal cell lines. Cell extracts (100 $\mu \mathrm{g}$ per lane) were subjected to $7-18 \%$ SDS-polyacrylamide gel electrophoresis, immunoblotted, and examined with anti-VGF ${ }_{443-588}$ serum, which recognizes the most $\mathrm{COOH}$-terminal region of the VGF gene (Rossi et al., 1992).
(A)

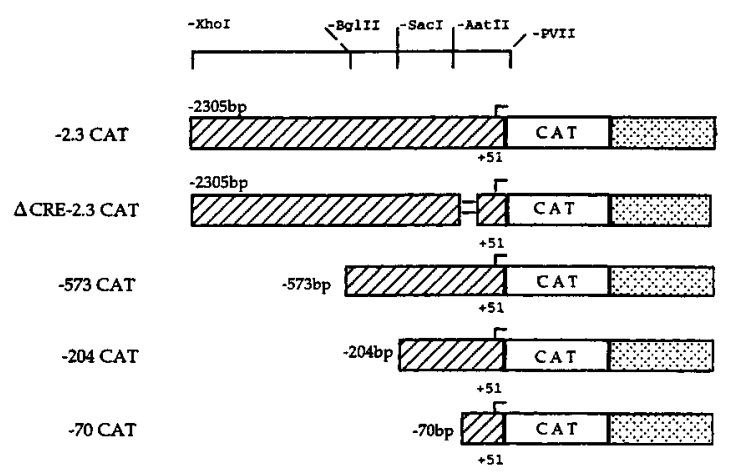

(B)

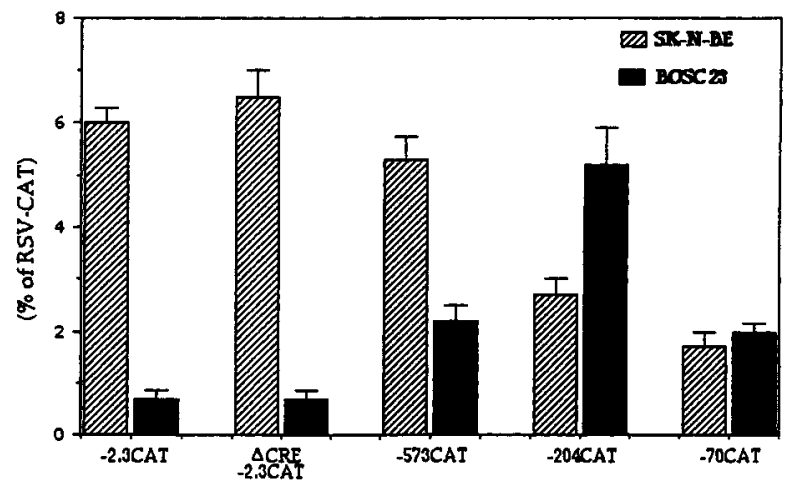

FIG. 4. Deletion analysis of the hVGF promoter. A: Representation of the hVGF-CAT plasmid containing progressive deletions of the VGF promoter region. Restriction enzyme sites used to construct the hVGF-CAT fusion gene are shown on the top. B: Analysis of CAT activity of extracts of SK-N-BE and BOSC 23 cells transfected with the plasmids in A. CAT activity was normalized as described in Materials and Methods. The values are expressed as reported in the legend of Fig. 3. This experiment was repeated three times.

We therefore used the chicken $\beta$-actin gene promoter, which is a constitutive promoter for various different cell lines (Quitschke et al., 1989). As shown in Fig. $5 \mathrm{~B}$, this fragment was active only in the $5^{\prime}$ to $3^{\prime}$ orientation, when it increased the transcriptional activity of the $\beta$-actin promoter 2.5 times in SK-N-BE cells. A similar increase in CA'T activity was observed on transfection in NIE-115 cells (data not shown), whereas, in contrast, no effect was observed when this plasmid was introduced into BOSC 23 or NIH-3T3 cells (data not shown). In the opposite orientation this fragment had no effect on CAT activity driven by the $\beta$-actin promoter when compared with the wild-type $\beta$-actin promoter. These results demonstrated that the fragment of the $h V G F$ gene comprising bases -573 to -204 functioned as an enhancer in a cell type-specific pattern. The suppressive effect of this segment was more evident when it was linked to its native promoter than 
when fused to a heterologous $\beta$-actin promoter. As mentioned above, this region contains a putative silencer element between bases -411 and -388 . Figure $5 \mathrm{C}$ presents the comparison between this motif and NRSE present in the SCG10, rat type II $\mathrm{Na}^{+}$channel, synapsin I, and human dopamine $\beta$-hydroxylase promoters.

\section{Regulation of the $h V G F$ promoter}

In PC12 cells VGF is transcriptionally induced by NGF and by dbcAMP and to a lesser extent by TPA (Cho et al., 1989; Possenti et al., 1992) and depolarization (Salton et al., 1991). To investigate further the role of these agents in tuning $V G F$ promoter activity, we measured the transcriptional induction exerted by dbcAMP and TPA on the $h V G F$ promoter constructs

(A)

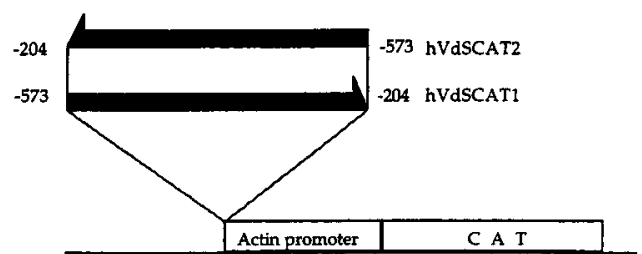

(B)

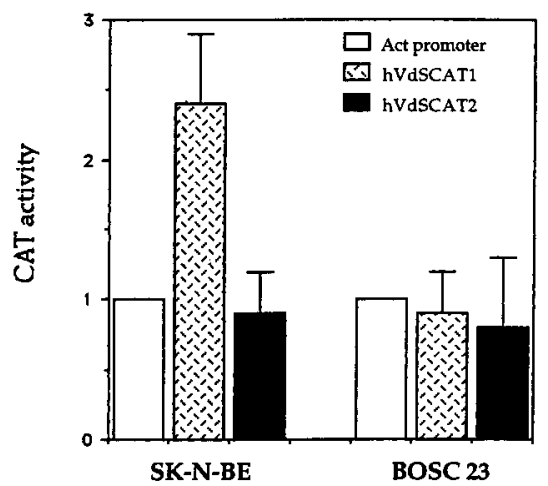

(C)

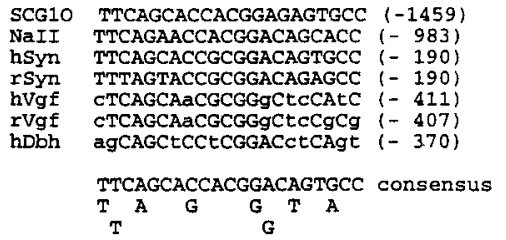

FIG. 5. The -573 to -204 fragment regulates transcription from a heterologous promoter. A: Illustration of hVdS-CAT1 and hVdS-CAT2 constructs. The arrows show the orientation of the -573 to -204 fragment. B: Analysis of CAT activity of SK-N-BE and BOSC 23 cells transfected with hVdSCAT1 and hVdSCAT2 plasmids. Values are expressed as fold induction in CAT activity, with respect to $\beta$-actin promoter activity standardized to 1.0 for each cell line. This experiment was performed three times. $C$ : Sequence similarities among the silencer element of rat SCG10 (Mori et al., 1990), type II Na+ channel (Kraner et al., 1992), synapsin I (Sauerwald et al., 1990), human dopamine $\beta$-hydroxylase (Ishiguro et al., 1993), and human VGF.
(A)

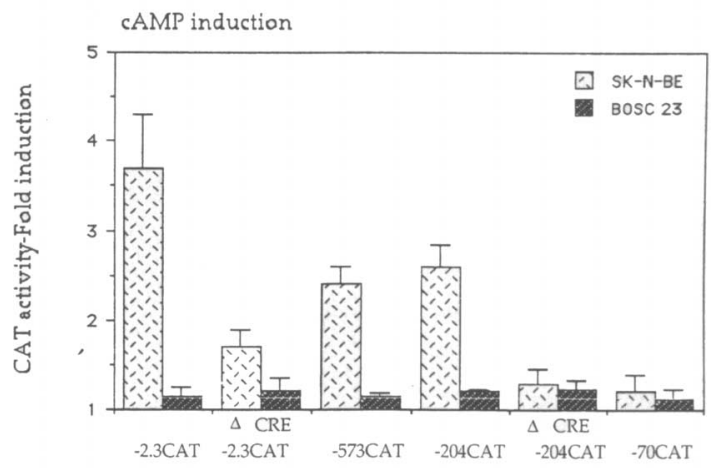

(B)

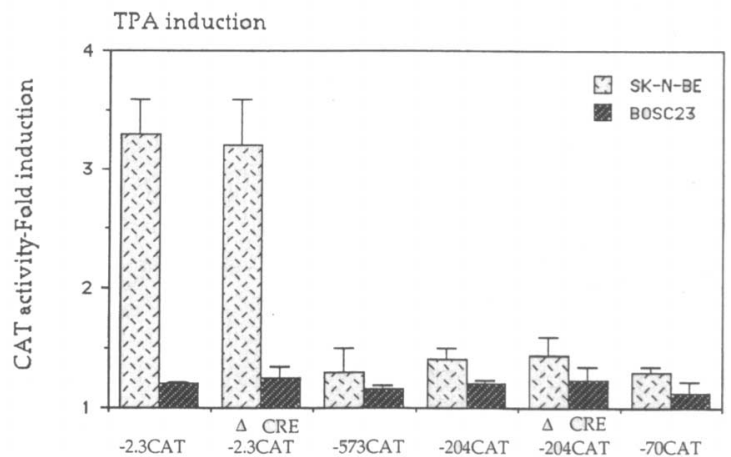

FIG. 6. The $h V G F$ gene is responsive to CAMP and phorbol ester. A: Effect of CAMP on hVGF promoter activity in transiently transfected SK-N-BE and BOSC 23 cells. B: TPA responsiveness of hVGF 5'-flanking DNA sequences in SK-N-BE and BOSC 23 cells. The cells were transfected with the hVGF-CAT plasmids defined in Fig. 3 and the $\triangle \mathrm{CRE}$-204CAT construct (see Materials and Methods) and exposed to either $1 \mathrm{mM}$ dbcAMP for $36 \mathrm{~h}$ or $0.1 \mathrm{~m} M$ TPA for $24 \mathrm{~h}$. Data are expressed as fold increase in CAT activity with respect to the value of untreated cultures standardized to 1.0 for each plasmid. Data are mean \pm SEM (bars) values from three experiments.

transfected in different cell backgrounds. As shown in Fig. 6A, transcription of the reporter was stimulated about threefold by dbcAMP in cells that express the endogenous $V G F$ gene. Deletion analysis indicated that both sequences upstream of nucleotide -573 and the CRE at position -77 contributed to enhanced expression of the promoter in response to increased levels of cAMP. It is surprising that in nonneuronal cells even those constructs of the $h V G F$ promoter that have a measurable basal level of expression fail to be induced by cAMP analogues, indicating that this CRE is not sufficient for transcriptional stimulation.

Treatment of transfected SK-N-BE cells with the phorbol ester TPA resulted in a threefold stimulation of the $h V G F$ promoter. Deletion analysis suggested that TPA responsive elements are located between bases $-2,305$ and -573 . No stimulation of CAT activity by TPA was observed on transfection of BOSC 23 cells. 


\section{DISCUSSION}

In this study we have cloned and sequenced the 5'flanking region of the $h V G F$ gene, and we identified functional domains that may contribute to the specificity of the expression and the regulation of this gene. The +1 transcription start site was assigned by primer extension and was located 29 nucleotides downstream of the typical TATA box as reported by Salton et al. (1991) for the rat $V G F$ gene. Comparison of the 5'flanking sequences of human and rat genes revealed both similarities and differences. Within the $0.8-\mathrm{kb}$ sequence examined, the degree of homology between the two species exceeds $80 \%$, strongly implying conserved regulatory functions. It is of note that this same region from the rat $V G F$ gene works as a tissue-specific promoter in transgenic mice (Piccioli et al., 1995). Blocks of homology exist between nucleotides -853 and -440 , and high sequence conservation is observed between nucleotides -440 and -204 . Conserved motifs in this region are tandem repeats of the tetranucleotide TTCA and a sequence $(-411$ to -388$)$ similar to a silencer element found in other neurospecific genes (Kraner et al., 1992; Mori et al., 1992). The 200-bp sequence immediately upstream of the transcription initiation site shares an overall homology of $75 \%$ and contains, in addition to the TATA box, motifs including AP-2, SP-1, CCAAT, and CRE. Some of these elements have been shown to be functionally active in the rat $V G F$ gene; the CRE, for example, is involved in transcriptional induction of $V G F$ by NGF and cAMP in PC12 cells (Cho et al., 1989; Possenti et al., 1992). A notable difference between the rat and human promoter sequences is the absence in the latter of a consensus E-box found at position -167 of the rat VGF promoter. This element has been shown to bind the $\mathrm{E}$ protein $\mathrm{HEB}$, and there is evidence that it contributes to the tissue-specific expression of the rat $V G F$ gene (Di Rocco et al., 1997).

A main finding of the present study was that $2.3 \mathrm{~kb}$ of the human upstream sequence provided rigorous tissue-specific restriction of promoter expression. This region was sufficient to limit the transcription of a reporter to those cells that expressed endogenous $V G F$, discriminating even between cell lines of similar origin like diverse neuroblastomas. We found that the tissuespecific expression of $h V G F$ is the result of both positive and negative regulation and that at least two regions contributed to the low expression of the promoter in nonneuronal cells.

A major increase of promoter activity in BOSC 23 and NIH-3T3 cells (data not shown) was observed after deleting sequences upstream of -573 . This same deletion had only slight effects on transcription in SK$\mathrm{N}$-BE neuronal cells. Motifs that potentially contribute to regulating the tissue-specific expression of $h V G F$ were suggested by sequence analysis of this region. For example, the sequence ANCCTCTCT (Baniahmad et al., 1987) at positions $-1,240$ and $-1,075$ was iden- tified as a silencer in several genes, including rat insulin, rat growth hormone (Baniahmad et al., 1987), chicken lysozyme, mouse immunoglobulin heavy chain, and polyoma virus (Baniahmad et al., 1987). In some of these cases, including $V G F$, the motifs are found more than once. This feature is also present in the rat CR1 repetitive sequence (Savagner et al., 1990). Repetitive sequences have been implicated in negative transcriptional regulation. Future work will focus on the significance of these elements in $h V G F$ and their influence on cell type-specific expression. The deletion of $-2,305$ to -573 removed the CCAGGAG element at position -867 , which is common to other neurospecific genes (Maue et al., 1990). It has been postulated that this element may be involved in neuron-specific expression by interacting with other cis-acting elements (Chin et al., 1994). Cell type-specific expression is often achieved through the combinatorial action of various elements. An example is the rat tyrosine hydroxylase promoter region, whose tissuespecific transcription is based on the synergy between Ap-1 and E-box sites (Yoon and Chikaraishi, 1992). As shown in Table 1 , the $1.7-\mathrm{kb}$ region contains 16 potential SP-1 sites and 11 potential AP-2 boxes, a finding that is extremely unlikely by chance and therefore strongly suggests a role for these motifs in the regulation of $h V G F$ expression.

A further deletion up to nucleotide -204 revealed a regulatory region whose presence had the effect of increasing promoter activity in BOSC 23 cells and decreasing it in SK-N-BE cells. The first effect suggests that in these cells a negative cis element exerts an inhibitory effect by blocking the nearby active promoter. In contrast, in VGF-expressing cells a positive cis-acting element activates the promoter. It is interesting that when placed upstream to the heterologous $\beta$ actin promoter, the -573 to -204 segment caused an enhancement of CAT activity in $V G F$-expressing cells such as SK-N-BE and NIE-115 (data not shown). Nevertheless, this same fragment had no suppressive effect on $V G F$-nonexpressing cells (BOSC 23 and NIH-3T3 ). Furthermore, this sequence did not comply with the absolute orientation independence characteristic of a classical enhancer. It is possible that cross-talk between positive elements could be responsible for such orientation dependence, as was described for the rat osteocalcin gene (Terpening et al., 1991). The absence of a suppressive effect of this segment when fused to the $\beta$-actin promoter suggests that silencing requires interaction with other elements in the $V G F$ promoter. Similar results have been reported for the human apolipoprotein B promoter (Paulweber et al., 1991 ) and for the rat dopamine $\beta$-hydroxylase gene, in which a negative responsive element did not influence expression from a heterologous promoter in JEG-3 cells (Shaskus et al., 1995). Centered around VGF base position -403 we found a 23 -bp-long sequence with $75 \%$ homology to the NRSE described by Mori et al. (1992). This motif is flanked by positive regulatory 
elements, namely, NF- $\kappa \mathrm{B}$, a CACCC box (Hernandez et al., 1995), and an AP-2/GC, which is located $<100$ nucleotides downstream. We hypothesize that the $V G F$ silencer could act by preventing, in nonneuronal cells, the positive interaction of these elements with each other or with cis-acting motifs present elsewhere in the $V G F$ promoter.

A second aspect of this study concerns the regulation of $V G F$ expression. Several distinct stimuli were shown to up-regulate the level of $V G F$ mRNA and VGF protein in adult tissues, a finding consistent with a function of $V G F$ in intercellular communication (Ferri and Possenti, 1996). We have detailed the transcriptional activation exerted by inducers of protein kinase $\mathrm{C}$ and protein kinase A. Exposure of transfected SK-N-BE cells to the phorbol ester TPA resulted in up-regulation of the $h V G F$ promoter. This induction must be mediated by elements present between $-2,305$ and -573 because deletion of this region abolished the transcriptional induction by phorbol ester. A canonical AP-1 element is present within this sequence at position -953 , and we assume that it mediates the transcriptional response to activated protein kinase $C$. More complex is the response of the $h V G F$ promoter to increased levels of cAMP in that transcriptional activation appears to be mediated by both distal and proximal motifs. A CRE at position -77 , as in the case of the rat promoter, mediates activation by CAMP of the $V G F$ promoter and is important for the response to NGF in PC12 cells (data not shown). As a small induction by CAMP (1.5-fold) was observed with the $-2.3 \mathrm{CAT}$ in which the core of the CRE motif was deleted, other motifs may contribute to the stimulation by protein kinase $\mathrm{A}$. Consistent with this finding was the slight reduction of the response to cAMP observed with the $-573 \mathrm{CAT}$ and $-204 \mathrm{CAT}$ constructs. An interesting observation was that transcriptional induction by cAMP is cell type dependent and occurs only in cells that express endogenous $V G F$, suggesting that the function of the CRE is regulated by tissue-specific events. Assuming that this CRE binds the ubiquitous transcription factor CREB, several nonmutually exclusive explanations may contribute to this effect. CREB may interact with a tissue-specific transcription factor that binds downstream of the CRE in the promoter of $V G F$, or a tissue-specific enzyme could posttranslationally modify CREB or any of its partners. As an example, the $\mathrm{Ca}^{2+} /$ calmodulin-dependent protein phosphatase calcineurin has been demonstrated to be necessary for the transcriptional competence of phosphorylated CREB (Schwaninger et al., 1995). Finally, a trans-acting inhibitory factor present in nonneuronal cells could prevent the activation of certain CREs in the context of neuronal-specific promoters. Such a hypothesis has been presented to account for the lack of response to cAMP of the somatostatin promoter in embryonal carcinoma cells (Masson et al., 1992).

Acknowledgment: This study was supported in part by grants from P. F. ACRO, P. F. BTBS, and P. F. Invecchiamento from the CNR to A.L. and CNR contract 9502759CT04 to R.P. The following colleagues are warmly acknowledged for helpful discussions: P. Piccioli, A. Turkewitz, A. Bradbury, S. Nasi, and D. Civitareale. Thanks are due to R. Butler for expert computer assistance in sequence analysis. N.C. has been supported by a fellowship from the "Anna Villa Rusconi" Foundation.

\section{REFERENCES}

Baniahmad A., Muller M., Steiner C., and Renkawitz R. (1987) Activity of two different silencer elements of the chicken lysozyme gene can be compensated by enhancer elements. $E M B O$ J. 6, 2297-2303.

Bonni A., Ginty D. D., Dudek H., and Greenberg M. E. (1995) Serine 133-phosphorylated CREB induces transcription via a cooperative mechanism that may confer specificity to neurotrophin signals. Mol. Cell. Neurosci. 6, 168-183.

Canu N., Levi A., Trani E., Rinaldi A. M., and Possenti R. (1992) Molecular cloning and sequence analysis of human VGF cDNA. Soc. Neurosci. Abstr. 18, 787.

Chin L. S., Li L., and Greengard P. (1994) Neuron-specific expression of the synapsin II gene is directed by a specific core promoter and upstream regulatory elements. J. Biol. Chem. 269 , $18507-18513$

Cho K., Skarnes W. S., Minsk B., Palmieri S., Jackson-Grusby L.. and Wagner J. A. (1989) NGF regulates gene expression by several distinct mechanisms. Mol. Cell. Biol. 9, 135-143.

Dente L., Cesareni G., and Cortese R. ( 1983 ) pEMBL: a new family of single stranded plasmids. Nucleic Acids Res. 11, 1645-1655.

DesJarden E. and Hay N. (1993) Repeated CT elements bound by zinc finger proteins control the absolute and relative activities of two principal human c-myc promoters. Mol. Cell. Biol. 13, $5710-5724$.

Di Rocco G., Pennuto M., Illi B., Canu N., Filocamo G., Trani E., Rinaldi A. M., Possenti R., Mandolesi G., Sirinian M. I., Jucker R., Levi A., and Nasi S. (1997) Interplay of the E box, the cyclic AMP response element, and HTF4/HEB in transcriptional regulation of the neurospecific, neurotrophin-inducible vgf gene. Mol. Cell. Biol. (in press).

Faisst S. and Meyer S. (1992) Compilation of vertebrate-encoded transcription factors. Nucleic Acids Res. 20, 3-26.

Ferri G. L. and Possenti R. (1996) A neurotrophin-inducible, earlydelayed response gene expressed in neuro-endocrine tissues, giving rise to a secretory granule protein and multiple peptide products. Trends Endocrinol. Metab. 7, 8-13.

Ferri G. L., Gaudio R. M., Cossu M., Rinaldi A. M., Polak J., Berger P., and Possenti R. (1995) The VGF protein in rat pituitary gonadotrophs and lactotrophs: sex difference changes during the oestral cycles and after gonadectomy. Endocrinology 136, 2244-2251.

Gorman C. M., Merlino G. T., Willingham M. C., Pastan I., and Howard B. H. (1982) The Rous sarcoma virus long terminal repeat is a strong promoter when introduced into a variety of eukaryotic cells by DNA mediated transfection. Proc. Natl. Acad. Sci. USA 79, 6777-6781.

Hawley R. J., Scheibe R. J., and Wagner J. A. (1992) NGF induces the expression of the VGF gene through a cAMP response element. J. Neurosci. 12, 2573-2581.

Hernandez M. C., Erkman L., Matter-Sadzinski L., Roztocil T., Ballivet M., and Matter J. M. ( 1995 ) Characterization of the nicotinic acetylcholine receptor $\beta 3$ gene. J. Biol. Chem. 270, 3224 3233.

Ishiguro H., Kim K. T., Joh T. H., and Kim K. S. (1993) Neurospecific expression of the human dopamine $\beta$-hydroxylase gene requires both cAMP-response element and a silencer region. $J$. Biol. Chem. 268, 17987-17994.

Kraner S. D., Chong J. A., Tsay H. J., and Mandel G. (1992) Silencing the type II channel gene: a model for neural-specific gene regulation. Neuron $9,37-44$. 
Laslop A., Mahata S. K., Wolkersdofer M., Mahata M., Srivastava M., Seidah N. G., Fischer-Colbrie R., and Winkler H. (1994) Large dense-core vesicles in rat adrenal after reserpine: levels of mRNAs of soluble and membrane-bound constituents in chromaffin and ganglion cells indicate a biosynthesis of vesicles with higher secretory quanta. J. Neurochem. 62, 2448-2456.

Levi A., Eldridge J. D., and Paterson B. M. (1985) Molecular cloning of a gene sequence regulated by nerve growth factor. Science 229, 393-395.

Lewis S. A. and Cowan N. J. (1986) Anomalous placement of introns in a member of the intermediate filament multigene family: an evolutionary conundrum. Mol. Cell. Biol. 6, 1529-1534.

Li L., Suzuki T., Mori N., and Greengard P. (1993) Identification of a functional silencer element involved in neuron-specific expression of the synapsin I gene. Proc. Natl. Acad. Sci. USA $90,1460-1464$.

Liu J. W., Andrew P. C., Mershon J. L., Yan C., Allen D. L., and Ben-Jonathan N. (1995) Peptide V: a VGF-derived neuropeptide purified from bovine posterior pituitary. Endocrinology 135, 2742-2748.

Lombardo A., Rabacchi S. A., Cremisi F., Pizzorusso T. Cenni M. C., Possenti R., Barsacchi G., and Maffei L. (1995) A developmentally regulated nerve growth factor-induced gene, VGF is expressed in geniculocortical afferent during synaptogenesis. Neuroscience 65, 997-1008.

Mahata M., Hortnagl H., Mahata S. K., Fischer-Colbrie R., and Winkler H. (1993) Messenger RNA levels of chromogranin B, secretogranin II and VGF in rat brain after $\mathrm{AF} 64 \mathrm{~A}$-induced septohippocampal cholinergic lesions. J. Neurochem. 61, 1648 1656.

Mahata S. K., Mahata M., Hortnag1 H., Fischer-Colbrie R., Steiner H. J., Dietze O, and Winkler H. (1993a) Concomitant changes of messenger ribonucleic acid levels of secretogranin II, VGF, vasopressin and oxytocin in the paraventricular nucleus of rat after adrenalectomy and during lactation. $J$. Neuroendocrinol. $5,323-330$.

Mahata S. K. Mahata M. Fischer-Colbrie R., and Winkler $H$. (1993b) In situ hybridization: mRNA levels of secretogranin II, VGF and peptidylglycine alpha-amidating monooxygenase in brain of salt-loaded rat. Histochemistry 99, 287-293.

Masson N., Ellis M., Goodbourn S., and Lee K. A. W. (1992) Cyclic AMP response element-binding protein and the catalytic subunit of protein kinase A are present in F9 embryonal carcinoma cells but are unable to activate the somatostatin promoter. Mol. Cell. Biol. 12, 1096-1106.

Maue R. A., Kraner S. D., Goodman R. H., and Mandel G. (1990) Neuron-specific expression of the rat brain type Il sodium channel is directed by upstream regulatory elements. Neuron $4,223-$ 231

Mori N., Stein R., Sigmund O., and Anderson D. J. (1990) A cell type-preferred silencer element that controls the neural-specific expression of the SCG10 gene. Neuron 4, 583-594.

Mori N., Schoenherr C., Vanderbergh D. J., and Anderson D. J. (1992) A common silencer element in the SCG10 and type II $\mathrm{Na}^{+}$channel gene binds factor present in nonneuronal cells but not in neuronal cells. Neuron 9, 45-54.

Nedivi E., Basi G.S., Akey I. V., and Pate Skene J. H. (1992) A neuronal-specific GAP-43 core promoter located between unusual DNA clements that interact to regulate its activity. $J$. Neurosci. 12, 69l-704.

Neumann J. R.. Morency C. A., and Russian K. O. (1987) A novel rapid assay for chloramphenicol acetyltransferase gene expression. Biotechniques 5, 444-447.

Paulweber B., Brooks A. R., Nagy B. P., and Levy-Wilson B. (1991) Identification of a negative regulatory region $5^{\prime}$ of the human apolipoprotein B promoter. J. Biol. Chem. 266, 21956-21961.

Piccioli P., Di Luzio A., Amman R., Schuligoi R., Surani M. A., Donnerer $\mathbf{J}$, and Cattaneo A. (1995) Neuroantibodies: ectopic expression of a recombinant SP antibody in the central nervous system of transgenic mice. Neuron 15, 373--384.

Possenti R., Di Rocco G., Nasi S., and Levi A. (1992) Regulatory elements in the promoter region of VGF, a nerve growth factorinducible gene. Proc. Natl. Acad. Sci. USA 89, 3815-3819.

Quitschke W. W., Lin Z. Y.. DePonti-Zilli L., and Paterson B. (1989) The $\beta$ actin promoter. J. Biol. Chem. 264, 9539-9546.

Rossi A.. Granata F., Augusti-Toceo G., Canu N., Levi A., and Possenti R. (1992) Expression in murine and human neuroblastoma cell lines of VGF, a tissue specific protein. Int. J. Dev. Neurosci. 10,527-534.

Salton S. R. J., Fischberg D. J., and Dong K. W. (1991) Structure of the gene encoding VGF, a nervous system-specific mRNA that is rapidly and selectively induced by nerve growth factor in PCI2 cells. Mol. Cell. Biol. 11, 2335-2349.

Sauerwald A., Hoesche C.. Oschwald R., Kilimann M. W. (1990) The $5^{\prime}$-flanking region of the synapsin I gene. J. Biol. Chem. 265, 14932-14937.

Savagner P., Miyashita T., and Yamada Y. (1990) Two silencers regulate the tissue-specific expression of the collagen II gene. J. Biol. Chem. 265, 6669-6674.

Schwaninger M., Blume R., Kruger M.. Lux G., Oetjen E., and Knepel W. (1995) Involvement of the Ca( $2+$ )-dependent phosphatase calcineurin in gene transcription that is stimulated by cAMP through CAMP response elements. J. Biol. Chem. 270, 8860-8868.

Shaskus J., Zellmer E.. and Lewis E. J. ( 1995 ) A negative regulatory element in the rat dopamine $\beta$-hydroxylase gene contributes to the cell type specificity of expression. I. Neurochem. 64, 5260 .

Terpening C. M., Haussler C. A., Juruktka P. W., Galligan M. A. Komm B. S., and Haussler M. R. (1991) The vitamin D-responsive element in the rat bone Gla protein gene is an imperfect direct repeat that cooperates with other cis-elements in 1.25 dihydroxyvitamin D3-mediated transcriptional activation. $M o l$. Endocrinol. 5, 373-385.

Thompson M. and Ziff E. B. ( 1989 ) Structure of the gene encoding peripherin, an NGF-regulated neuronal-specific type III intermediate filament protein. Neuron 2, 1043-1053.

Trani E., Ciotti T., Rinaldi A. M., Canu N., Ferri G. L., Levi A., and Possenti R. (1995) Tissue-specific processing of the neuroendocrine protein VGF. J. Neurochem. 65, 2441-2449.

Yoon S. O. and Chikaraishi D. M. (1992) Tissue-specific transcription of the rat tyrosine hydroxylase gene requires synergy between an AP-1 motif and an overlapping E-box containing dyad. Neuron 9, 55-67.

Zannini M., Francis-Lang H., Plachov D., and Di Lauro R. (1992) Pax-8, a paired domain-containing protein, binds to a sequence overlapping the recognition site of a homeodomain and activates transcription from two thyroid-specific promoters. Mol. Cell. Biol. 12, 4230-4241. 